\title{
¿Qué es la cultura frente a la historia? Glosas sobre los trabajos de Jürgen Golte
}

\author{
Alejandro Diez \\ (iD) https://orcid.org/0000-0003-3349-0272 \\ Pontificia Universidad Católica del Perú \\ adiez@pucp.edu.pe
}

Tuve la fortuna de conocer a Jürgen Golte a lo largo de más de un cuarto de siglo. Como estudiante de antropología, como joven egresado, como profesor o como simple colega, pude interactuar con él en conferencias, congresos, seminarios, coloquios académicos en la Universidad Católica, en San Marcos, en el IEP o en Clacso. Recuerdo claramente la primera vez que lo vi comentar la presentación de un conocido académico en un evento del IEP hace más de treinta años: mientras asimilaba sus demoledoras críticas, agradecía mentalmente que no hubiera leído mi trabajo. Crítico agudo y habitualmente acertado era Jürgen. Por supuesto, no siempre tuve la misma suerte. En cualquier caso, se puede decir con total certeza que siempre era muy interesante escucharlo, tanto en sus presentaciones como en sus comentarios académicos y sus conversaciones casuales.

También es muy interesante leerlo. Ha dejado un largo legado de trabajos de investigación a lo largo de más de cinco décadas, desde sus primeros trabajos históricos sobre los Andes hasta los últimos sobre la iconografía moche, y seguramente tenía aún varios otros textos en camino, por lo menos alguno sobre la iconografía de Tiahuanaco-Wari, anunciado por él mismo. Propongo en este artículo una breve guía de lectura y un recorrido por algunos de sus principales estudios. Sin ser exhaustivo — sino más bien intencionalmente selectivo- procuro un recorrido analítico sobre los que considero sus principales aportes al conocimiento de las realidades peruanas y al desarrollo de la antropología en el Perú. Revisar y reseñar los trabajos de Jürgen Golte no es una tarea sencilla. No solo por lo abundante de su bibliografía, sino por la forma como ha ido distribuyendo y decantando ideas, conceptos, intuiciones y certezas en distintos trabajos a lo largo del tiempo; reiterando algunas ideas en distintos textos. Proporcionando 
claves distintas y originales, sus estudios nos enseñan tanto sobre la realidad «antropológica» peruana como sobre métodos y postulados para el análisis.

Por ello, he procurado una selección más o menos comprehensiva de varios de los temas que han cruzado sus trabajos a lo largo del tiempo. Comienzo con sus ensayos sobre campesinado, comunidades y racionalidad andina. Sin detenerme en los estudios más etnográficos realizados principalmente en el valle de Chancay Huaral — donde, dicho sea de paso, escuché alguna vez anécdotas concernientes a su paso por Huayopampa-, me centro en sus análisis sobre la racionalidad y la codeterminación de la organización andina, quizá los temas con los que más se relaciona su trabajo.

Abordo luego sus textos sobre migración, trayectorias de migrantes y análisis sobre economía y sociedad urbanas, que corresponden a la década del desborde popular y los cambios en los estudios clásicos de la antropología, en el proceso de incorporación de nuevos temas y espacios (Degregori, 2000) y que están entre sus trabajos etnográficos más extensos, en colaboración con Norma Adams y Doris León. La tercera parte corresponde al conjunto de trabajos sobre iconografía Nazca y Moche, muy importantes en volumen y análisis a pesar de ser poco debatidos en el mundo antropológico peruano. Finalmente, enfrentamos el espinoso tema de la definición de cultura, discutido prácticamente a lo largo de toda la obra de Golte, en ocasiones de manera polémica.

Dejamos de lado algunos temas: en particular sus aportes iniciales sobre historia, que no hemos revisado, en parte por su accesibilidad limitada en estos tiempos de aislamiento. Tampoco hemos analizado sus escritos en alemán por nuestras limitaciones lingüísticas. Confiamos en que la mayor parte de ellos tengan equivalentes en sus publicaciones en español. Quedan también en la sección de «otros» algunos textos que eran de alguna manera reiterativos de sus textos principales, también introducciones de libros, así como algunos estudios temáticamente aislados que a nuestro conocimiento no han formado parte de esfuerzos más consistentes y continuados.

Esta es, ciertamente, una lectura parcial e incompleta, pero busca proporcionar al lector una guía introductoria a los principales trabajos de un colega que forma sin duda parte de la historia de la antropología en el Perú. 


\section{DE LAS COMUNIDADES A LA RACIONALIDAD ANDINA Y SU CODETERMINACIÓN}

Quizás el libro más conocido y difundido de Jürgen Golte sea el pequeño texto sobre racionalidad de la organización andina (1980). Publicado luego de una serie de trabajos sobre historia y de los estudios sobre comunidades del valle de Huaral $(1967 ; 1968 ; 1973)$ — para los que desarrolló trabajo de campo al menos en Pacaraos y Huayopampa desde fines de los años sesenta ${ }^{1}$ — este libro-ensayo concentra una serie de postulados potentes sobre las lógicas de organización y producción de la cultura/comunidad andina, que explican su gran influencia.

La sociedad, la cultura, la comunidad andina - términos que aparecen repetidamente en el texto - se sostienen económicamente sobre una serie de principios y dispositivos sociales generados históricamente a lo largo de varios cientos de años, domesticando especies, adaptando variedades a distintas zonas de vida, en un contexto geográfico adverso, marcado por la baja productividad determinada por la altitud, la escasez de precipitaciones y la accidentada orografía andina.

Adoptando los análisis de Troll y Murra (1975), la lógica de la racionalidad andina combina de un lado el aprovechamiento escalonado de ciclos de producción de distintos cultivos en pisos ecológicos, logrando con ello maximizar el uso de la fuerza de trabajo, el principal recurso energético en los Andes según los estudios de Dollfus (1981). Ello es posible por la domesticación de gran cantidad de plantas y animales, una suerte de «humanización generalizada» del espacio, que se empieza a generar desde el formativo y termina permitiendo el aprovechamiento de todos los espacios habitables. Sin embargo, la baja productividad no facilita la especialización, generando una cultura centrada en la producción agropecuaria $\left(1992 \mathrm{a}, \mathrm{p} .443^{2}\right)$. A diferencia de lo que ocurre en sociedades campesinas europeas, marcadas por la estacionalidad, en los Andes la mano de obra se distribuye más o menos uniformemente a lo largo del año, aprovechando al máximo el trabajo humano. Para que ello sea posible, es necesario, además, establecer una serie de arreglos de cooperación entre distintas unidades domésticas, por la vía del uso compartido, alternado o complementario de distintos espacios. Para Golte,

1 El texto sobre Huayopampa implicaría un trabajo de retorno al campo algunos años, después, dando lugar a una publicación aumentada (Fuenzalida 1992). El conjunto del proceso y el contexto en el Perú, y en el Instituto de Estudios Peruanos, en el último medio siglo es reseñado por el propio Golte en una publicación del IEP (2014).

2 El texto sobre cultura y naturaleza se publica por primera vez en la revista Allpanchis (Golte 1981a), siendo reeditado una década después en el libro sobre ciudades en los Andes editado por Kingman (1992a). 
el manejo simultáneo de ciclos agropecuarios y la cooperación necesaria entre unidades de producción son los elementos constitutivos de la organización de la agricultura andina (1980, p. 93).

Este arreglo institucional, construido por la sociedad andina en un territorio específico y gestado a lo largo de siglos de ocupación y aprovechamiento del espacio, resulta sumamente resiliente a múltiples cambios a lo largo del tiempo -incluidas la invasión y ocupación española—, que aun incorporando nuevos cultivos y crianzas no habría modificado sustancialmente el sistema ni sus lógicas. La racionalidad andina de ocupación del espacio, basada en pisos ecológicos, cooperación y maximización en el uso la mano de obra sería también un componente importante en la estrategia de sus pobladores para conquistar las ciudades en los procesos de migración de la primera mitad del siglo XX y hasta entrada la década de 1980, incorporando incluso elementos de base monetaria en las relaciones sociales implicadas $(1980$, p. 89$)$.

Ciertamente no se trata de una racionalidad inmutable, aunque su continuidad a lo largo de los siglos la hace aparecer como ahistórica. De alguna manera, esta racionalidad de supervivencia y maximización del trabajo habría sobrevivido a múltiples cambios y procesos históricos, incluidos intentos de monetarización y de ampliación de la esfera del mercado en el período colonial. En Repartos y rebeliones, Golte señala que hacia fines del siglo XVIII los intentos por ampliar los circuitos comerciales fracasan por contradicciones internas, permitiendo la continuidad de las racionalidades locales (1980a, p. 206). La continuidad del espacio andino reproduce de alguna manera el supuesto sobre los procesos de continuidad de las sociedades indígenas campesinas asumida en los trabajos sobre comunidades de la década de 1960: la colectividad generada por las reducciones toledanas se mantendría hasta los procesos des estructuradores de la expansión de mercado en el siglo XX (Degregori y Golte, 1973; Urrutia, 1992).

Serían recién las transformaciones de las últimas décadas del siglo XX en algunos espacios del territorio peruano - en los que el crecimiento poblacional, las fuerzas del mercado y los procesos de proletarización, asociados al creciente interés de mejorar los ingresos y beneficios en las unidades domésticas - las que extinguen la racionalidad de la agricultura andina. Altos salarios y monoproducción (en cultivos de coca, café, cacao y productos de costa) hacen que, en algún momento «la organización andina deje de ser tal» (Golte, 1980, p. 93).

La evidencia etnográfica mostraba que existía coexistencia entre lógicas de autosubsistencia, producción mercantil y búsqueda de maximizar ingresos, lo que implicaba pensar en la existencia de un vínculo entre ambas esferas 
de organización y reproducción social. Ante esta circunstancia, Golte y de la Cadena plantean la hipótesis de la codeterminación: «Si descomponemos entonces la economía comunal encontramos que los diversos factores que permiten la reproducción del universo campesino en parte provienen del mercado, y en parte son elementos y productos que entran, o están presentes, tanto a nivel comunal como a nivel familiar» $(1986$, p. 5) 3 .

Así, la codeterminación explica cómo el mercado es adoptado y se adapta a las lógicas de reproducción andinas. El mercado no logra reemplazar las reglas de interacción previas ni sustituye toda la producción por el intercambio de mercancías, en buena parte por la inconmensurabilidad entre ambas esferas. El valor de los factores implicados excede a su precio de mercado, por lo que «el mantenimiento de una esfera de interacción, diferente de la del mercado, resulte ser la precondición de la aparición de productos y de la fuerza de trabajo campesina como mercancía» (1986, p. 13). Ello permite un tránsito entre ambas esferas que operan al mismo tiempo de acuerdo a con las condiciones y estructuras de precios regionales.

El tenor del análisis tiene un aire culturalista, proponiendo afirmaciones sobre el conjunto de la sociedad antes que sobre las lógicas de las unidades familiares, que se asumen como parte de conjuntos sociales mayores, es decir, como parte integrante de comunidades. Contrasta este análisis con los que se hacían en esos mismos años desde las canteras de la economía y la sociología, centrados en las lógicas chayanovianas de explotación familiar, planteando una racionalidad campesina y de aversión al riesgo, antes que andina y que eran caracterizadas por su participación parcial, pero inevitable, en la economía de mercado (Figueroa, 1981; Plaza y Francke, 1981).

Aun cuando el contexto de mercado avanza sobre la economía familiar, no todos los procesos de producción organizados según la esfera mercantil desembocan en la apropiación familiar, pues se mantienen ámbitos colectivos, familiares, comunales y religiosos (Golte y de la Cadena, 1986, p. 25). Es en estas dimensiones colectivas donde la comunidad resulta importante como organización territorial, social y económica para la reproducción de los campesinos andinos, aun cuando los intercambios mercantiles y no mercantiles la excedan (p. 45).

Pero estas lógicas de lo comunal no existen de la misma manera ni en la misma densidad en todos los pueblos. Golte enfatiza que el uso del concepto comunidad

3 El artículo sobre la codeterminación, inicialmente publicado en la revista Allpanchis (1983), fue editado posteriormente como documento de trabajo en el IEP (1986). 
«ha impedido un tratamiento adecuado de la diversidad de los pueblos andinos», diversidad que es «siempre la desviación localista de un modelo general» (1992, p. 18). Asumiendo que en los Andes deben existir unos cuantos «tipos de pueblos con características funcional y estructuralmente concatenadas» plantea la necesidad de desarrollar modelos a partir de estos casos tipo, para sistematizar el conocimiento sobre la diversidad histórica y regional. Para ello, propone una clasificación de comunidades a partir de la ubicación por vertientes geográficas, asumiendo que los procesos de adaptación y transformación son ante todo territoriales (1980, pp. 97 y ss.). De los siete tipos de propuestas, Golte desarrollaría en extenso las características generales de las comunidades de la zona central vertiente occidental de los Andes (1992). El desarrollo de tipologías y los análisis regionales de comunidades es aún una tarea inconclusa en la antropología peruana.

\section{LA MIGRACIÓN, LA INFORMALIDAD Y EL CAPITALISMO EN EL MUNDO ANDINO URBANIZADO}

En los trabajos de Golte, el modelo de racionalidad organizativa andina experimenta tanto un proceso de transformación y expansión como de desestructuración y reemplazo.

El modelo andino de organización empieza a experimentar transformaciones a partir del siglo XIX, básicamente por el crecimiento de la población, pero por entonces la subordinación existente dejaba espacios de autonomía y permitía formas de cooperación propias. Por ello, el crecimiento inicial «pudo ser resuelto todavía a partir de la cultura aldeana andina, si bien en niveles de consumo relativamente bajos» (Golte, 1992a, p. 448). Sin embargo, en el siglo $\mathrm{XX}$, al mismo tiempo que continuaba el crecimiento poblacional, la sociedad urbana transformada presionaba sobre el campo buscando hacer a los campesinos funcionales a la expansión del mercado, lo que generó en la población andina una individuación de intereses y desarrolló el acceso familiar a la propiedad. Con ello, los más afortunados lograban centralizar excedentes y ampliar sus bases de producción mediante la contratación de fuerza de trabajo, reforzando la integración al mercado.

Todo ello tuvo como consecuencia el resquebrajamiento de las formas tradicionales de cooperación (p. 453). El proceso incide, además, en una cada vez mayor división del trabajo, en la escolarización de la población, la aparición de organizaciones y sindicatos y la producción de artesanía para el mercado turístico, al mismo tiempo que se incrementaba el consumo de productos de la 
ciudad, incluyendo productos «culturales» como la música (p. 445). El resultado es un «continuo rural urbano» — probablemente parafraseado de Redfield-, pero en esencia, en otras palabras, es el fenómeno que se observa en el espacio rural peruano desde al menos fines de la década de 1990 y que se ha convenido en llamar «nueva ruralidad» (Giarraca, 2001; Diez, 2014).

En el análisis de Golte, la sobrepoblación, la expansión del mercado y los procesos de especialización, división del trabajo y asalariamiento sientan las bases para el resquebrajamiento del orden anterior (1980, p. 88). El mercado altera el equilibrio en el acceso a recursos, subordinando las lógicas de lo comunal y sustituyendo productos alterando, además, las lógicas de autoproveimiento y subsistencia.

La sobrepoblación relativa y la pauperización de la población rural obligaban a contingentes cada vez mayores de población a migrar hacia las ciudades por necesidad económica. En las ciudades, desligados de la estacionalidad de la agricultura, los migrantes andinos ensayan nuevas formas de generación de ingresos. Para ello, aprovechan sus conocimientos y ética del trabajo, sus lógicas de planificación y organización, así como sus mecanismos de reclutamiento de mano de obra de parientes y paisanos (1995, p. 141). Los migrantes no encuentran problemático que la ciudad no les genere puestos de trabajo para absorber mano de obra: al contrario, con su afán emprendedor atenderían la gran demanda insatisfecha por productos y servicios de la gran ciudad, compitiendo exitosamente y generando el crecimiento de una economía informal regulada por el mercado y no por las limitaciones impuestas por el Estado (1995, p. 144). En el proceso, la población migrante incrementa sus conocimientos, rompe las barreras de dominación interétnica y multiplica las formas de división del trabajo, vinculándose exitosamente en un contexto global (2003).

«Partiendo de sus bases de cultura campesina la gente asumió el reto de construir una cultura urbana próspera que pudiera servir de base para su propio bienestar y el de sus hijos» (2001, p. 119). Aprovechando su organización parental y sus «redes étnicas», que abarcan la población proveniente de un pueblo o de pueblos de la misma región, la población migrante logra reorganizarse en términos capitalistas; separados por la migración, mantienen por su red étnica relaciones con los descendientes de sus grupos de origen (Golte, 1995, p. 121). Con mayores niveles de instrucción y con acceso a medios de comunicación masiva, los migrantes reelaboran sus contenidos culturales: parentesco, música, rituales y celebraciones, ampliando sus expectativas y posibilidades (p. 136). Asistimos así a la creación de una «nueva cultura urbana», derivada de la cultura 
andina, que incorpora algunos aspectos de lo criollo urbano y del sistema cultural europeo. Todo ello implica un proceso de reelaboración cultural, de creación y aprendizaje colectivo que los migrantes comparten con la población de sus lugares de origen (Golte, 1999).

Los caballos de Troya de los invasores (Golte y Adams, 1987) narra la odisea de los migrantes andinos que se insertan exitosamente en la gran ciudad, desarrollan actividades económicas de producción y servicios y utilizan sus redes de parentesco y paisanaje, que funcionan como cadenas de transmisión de información, como redes de apoyo a la migración, y proporcionan contactos y modelos de inserción en la gran ciudad, además de constituir las más de las veces redes de cooperación y fuentes de trabajo. Recuerdo aún la fascinación que generaban los primeros resultados que Golte presentó alguna vez en la sala de grados de la PUCP, munidos de cuadros de parentesco, redes de paisanaje alrededor de algunas actividades laborales y esquemas de las distintas formas de inserción de los emigrantes rurales (arborescente, paralela, convergente). Las trayectorias de los migrantes de doce pueblos de distintas partes del Perú (hinterland de Lima, sierra sur, sierra norte, costa norte, costa sur) muestran cómo los puntos de partida, la especialización y diferenciación pre existentes modelan y condicionan los procesos de migración y las trayectorias de inserción de los migrantes, «no es posible entender la suerte que corre un migrante en Lima sin comprender al mismo tiempo la sociedad local de la cual proviene, y los nexos que los originarios de un mismo pueblo establecen entre sí en su proceso de inserción en la economía y sociedad urbanas» (p. 74). El libro contiene además una extensa descripción etnográfica de las condiciones y situación de los doce pueblos incluidos en el estudio.

Quizás el trabajo más interesante de transformación de la cultura aportada por los emigrantes es el análisis sobre las alasitas y el proceso de expansión de su práctica en las últimas décadas (Golte y León, 2014). Los autores postulan la expansión de las alasitas en el último cuarto del siglo XX y la primera década del XXI, haciendo un paralelismo etnográfico a lo que implicó la ética protestante en el desarrollo del capitalismo. Las alasitas constituyen un componente ideológico andino $-\mathrm{y}$ más precisamente aimara - en el desarrollo del capitalismo y el neoliberalismo en los Andes centrales, favoreciendo una «acumulación primitiva» (p. 31). Las alasitas, de origen antiguo, se asocian a una serie de símbolos y rituales de crecimiento y fertilidad, vinculadas con el comercio al menos desde finales del siglo XIX y proporcionan un importante impulso a la difusión de las ferias comerciales, pero también a la lógica del logro del bienestar, la riqueza 
y la acumulación personal, es decir, al logro de los objetivos que los agentes se proponen.

La creencia y el «uso» de las alasitas contiene un doble mecanismo para asegurar el logro de los objetivos deseados: además de expresar lo que se quiere obtener y desarrollar los rituales necesarios para ello, implica el compromiso de asegurar el esfuerzo personal necesario para lograrlo (p. 48). El libro contiene no solo el análisis del conjunto de otros objetos asociados a las alasitas, sino también su sorprendente expansión desde el altiplano a otras ciudades del Perú y del extranjero y el conjunto de rituales, ceremonias y ferias con las que están relacionadas. Como corolario, señalan los autores que las nociones políticas de izquierda de estas poblaciones expresan no un ideario político sino «ideales de ascenso social mediante la acumulación de bienes materiales a través de su inserción en el mercado» (p. 14).

En un desarrollo paralelo, Golte expresa estos cambios en términos de la relación entre la ciudad (de Lima) y su entorno y de los tipos de ciudadanía relacionados con el proceso (2013). Contrasta las relaciones entre la ciudad y su hinterland diferenciando entre la «ciudad palacio», la «ciudad de intercambio» y la «ciudad de productores»: la primera extrae riqueza de su espacio circundante desfavoreciendo su crecimiento; la segunda facilita cambios técnicos y de bienestar, pero no contribuye a ellos, en tanto que la tercera genera un incremento de la productividad, que permite que tanto el centro como la periferia puedan crecer juntos. Lima es una ciudad que transita del primer al segundo y tercer tipo, multiplicando las posibilidades de crecimiento y ciudadanía de sus habitantes. Y, sin embargo, para el autor la ciudadanía es una meta utópica, porque los pobladores no pueden en última instancia decidir sobre las condiciones de su vida «porque las realidades económicas y financieras mundiales no están bajo su control» (2013, p. 61).

\section{LAS «MITOLÓGICAS» DESDE LA ICONOGRAFÍANASCA Y MOCHICA}

Cuando nos referimos al legado de Jürgen Golte, poco tomamos en cuenta que, al menos en el último cuarto de siglo, uno de sus principales intereses fue el análisis de la iconografía nasca, moche y wari-tiahuanaco. Desde inicios de la década de 1990, cuando se publican en Perú los dos cuentos gráficos sobre los dioses de Sipán (1993 y 1994) y el libro Iconos y narraciones (1994), Golte escribió numerosos artículos sobre diversos aspectos de la iconografía de las culturas prehispánicas. Para ello, desarrolló una metodología de análisis aplicada sobre un voluminoso corpus de evidencia que conforma un conjunto de análisis sobre diversos aspectos 
de la iconografía de las culturas andinas. Los libros y artículos publicados sobre el tema configuran un corpus impresionante sobre la iconografía prehispánica e incluyen no solo una importante recopilación de imágenes, sino sobre todo el desarrollo de un método analítico y una serie de ejercicios de interpretación y lectura las representaciones iconográficas moche y nasca (y anunciando un trabajo sobre wari, que no ha sido publicado hasta el momento), todo ello repartido en múltiples artículos y en particular en dos libros que contienen buena parte del desarrollo metodológico y analítico, sobre todo para el caso moche (1994; 2009). En las siguientes páginas ensayaremos un desarrollo sintético de sus elementos analíticos e interpretativos tomando elementos -integrados o dispersos-contenidos en diversas publicaciones.

El supuesto básico del conjunto del proceso analítico e interpretativo de Golte es que, cuando se trabaja con iconografía prehispánica, hay que considerar, ante todo, que no se trata de objetos o imágenes fabricados para nosotros. El conjunto de objetos debe encontrar su sentido en el propio sistema cultural de los artesanos que los elaboraron, en su universo cosmológico de origen. Además, el conjunto de evidencia muestra la suficiente consistencia como para asumir que se trata de un universo construido sistemáticamente, que incluye no solo imágenes, sino representaciones, discursos, actividades culturalmente significantes. Se asume que los conjuntos de imágenes expresan ideas preponderantes sobre el cosmos de sus sociedades y formaban parte de tradiciones culturales coherentes: Golte asume la homología entre los contenidos comunicados por las imágenes, las cosmovisiones y las prácticas culturales de sus autores (2003, pp. 179-180).

Los elementos metodológicos de su trabajo se desarrollan parcialmente en diversos trabajos, aunque destacan por su mayor desarrollo los libros Iconos y narraciones (1994) y Moche (2009) y en el artículo «Iconografía Nasca» (2003), que contienen la mayor parte de los supuestos y procedimientos de método utilizados en el análisis iconográfico. Dicho análisis incluye una serie de pasos orientados a identificar el sentido que han podido expresar las imágenes: (i) identificar los elementos constitutivos inamovibles (identificar y caracterizar imágenes); (ii) descubrir eslabonamientos repetidos entre elementos (identificar «asociaciones canónicas»), y (iii) encontrar interrelaciones entre símbolos e imágenes a partir de un modelo de comprensión hipotético (2003,p. 180). Identificados personajes y sus asociaciones, es posible encontrar «convenciones canónicas», escenas reiterativas. Se asume que el significado de cada objeto supone la totalidad de las relaciones que existen respecto de él, por tanto los conjuntos coherentes son más fácilmente interpretables que las partes en sí (1985). 
El autor advierte de algunos problemas a resolver, en particular el desconocimiento sobre la jerarquía entre los elementos significantes identificados. Por ello, el derrotero solo es posible si se dispone de un corpus iconográfico suficientemente grande, y se inicia el análisis con grupos iconográficos que incluyan asociaciones complejas. Hay en ello también un principio de coherencia: se asume que las interpretaciones que se encuentren deben ser válidas para todo el conjunto y no solo para una parte (2008, p. 21). En el proceso «se encontrará no solo el sentido del mito y el carácter secuencial en que está representado, sino la forma en la que se lo narra, las relaciones entre los actores de la cosmología moche, y las subdivisiones de este universo bipartito aplicadas a la organización del tiempo y casi cualquier otro fenómeno del mundo existente» (2014, p. 105).

Es imposible no hacer un paralelismo entre este método y los procedimientos de Propp y Levi Strauss para el análisis de mitos, que también requieren corpus de mitos que muestren las regularidades y las variaciones en los mensajes (Levi Strauss, 1979). El conjunto de análisis desarrollados, las imágenes y personajes identificados, los rituales-mitos desentrañados de la iconografía proporcionan un universo cosmológico fascinante, que me parece pertinente comparar con el mitológico de Levi Strauss: un esfuerzo sostenido de regularidades, contrastes y análisis entre personajes y sus mitos, asociados con el espacio geográfico de sus sociedades.

El procedimiento analítico desarrollado para la iconografía moche asume una serie de supuestos metodológicos y analíticos que marcan diferencias con otros análisis iconográficos, como los de Bourget (2006), Donnan (1999) o Hocquenhem (1987). Partiendo del hecho de que la mayor parte de la iconografía está plasmada en ceramios, asume que su corporeidad y volumen son constitutivos del mensaje registrado: no es suficiente desplegar la imagen en dos dimensiones para luego analizarla, sino que es necesario considerar en el proceso analítico su posición en el ceramio, e incluso su carácter como dibujo o como escultura. Entiende, pues, las piezas de cerámica como plataformas tridimensionales de registro de campos con sentido propio, que expresan oposiciones y posiciones de los seres dibujados o esculpidos que corresponden a su situación en el cosmos de la cultura que los ha producido. Así, «las botellas de asa estribo no son simplemente un fondo sobre el cual se expone una pintura, sino que es un objeto que se utiliza de una forma pautada en la construcción de sentido» $(2008$, p. 21). El proceso sigue el itinerario señalado anteriormente: identificación de personajes y determinación de sus asociaciones, para analizar enseguida a dichos personajes 
en sus actuaciones, dando a estas un sentido, configurando narraciones, «mitos» con sentido a partir de las imágenes (1994).

En el plano interpretativo, el análisis de Golte encuentra sentido en una serie de personajes identificados en la iconografía, como la mujer tuerta, el guerrero iguana, las sacerdotisas de la luna, las distintas divinidades; objetos como diademas, cinturones, caracoles, pallares, instrumentos de cultivo, así como en una serie de escenas que van desde la escena del sacrificio, la secuencia del entierro, la lucha del dios contra los monstruos marinos la rebelión de los objetos, la recolección de caracoles, la cacería de venados, la captura de guerreros, el baile de la soga y otras.

Señala Golte que «la cantidad de estas escenas es sorprendentemente pequeña» y es precisamente utilizando las reglas de asociación derivadas de las escenas conocidas que es posible formar «un conjunto coherente de la totalidad de elementos y escenas» (1985, p. 357). Así, por ejemplo, en el análisis sobre la recolección de caracoles, encuentra que estos están asociados a un paisaje desértico, de cerros o lomas, y a animales como serpientes, zorros, venados y felinos, todo ello asociado a su vez a instrumentos de labranza y mazorcas de maíz, con lo que concluye una asociación entre los caracoles, las lomas y la fertilidad (1985, pp. 361-362).

El núcleo de su interpretación se basa en una serie de supuestos sobre el sentido de las imágenes que incluyen postulados analíticos que pueden resumirse en tres principios: (i) la lógica del parentesco extendido: en las imágenes existen principios de parentesco entre humanos, animales y plantas, que se vinculan unos con otros en relaciones genealógicas y generativas, asociando a los distintos personajes en linajes mayores y menores, masculinos y femeninos; (ii) la comprensión del espacio como un ámbito socio-morfo, en el que los seres de poder permanecen en lugares y objetos a lo largo del tiempo, de tal manera que el cosmos entero es un testimonio del pasado, y (iii) la comprensión del universo como bipartito, compuesto de pares de opuestos (arriba-abajo; masculino-femenino) que sin embargo generan conjunción creativa: el tinkuy, el punto de encuentro es también parte constitutiva de la oposición binaria $(2009 ; 2014)$

Más allá del conjunto de análisis, identificación e interpretaciones de múltiples personajes y escenas, el análisis de Golte postula a existencia de un modelo cosmológico explicativo general basado en la existencia de dos seres andróginos, uno todo poderoso, celeste, diurno, asociado con el mar y otro ser marginal, terrestre, perteneciente al mundo del subsuelo, que se representa como un gusano. El universo resulta integrado en dos ámbitos entrelazados: el mundo 
de arriba, masculino (dividido entre el cielo diurno el cielo nocturno) y el mundo de abajo, femenino, subterráneo, y húmedo, relacionado con la noche y el mar. El mundo de los muertos pertenece al mundo femenino, regido por la diosa de la tierra (2009, p. 149). Las escenas de los vivos se representan siempre pintadas, mientras que las de los muertos tienen relieve.

El supuesto mayor responde a la lógica general de la producción de todos estos objetos e imágenes: «sociedades complejas con una jerarquización pronunciada, con habitantes numerosos, con una organización social diversificada, con una división del trabajo avanzada [...] requerían instrumentos de ordenamiento social, de formas de transmisión de conocimientos, y también de sistemas de manejar los conocimientos sobre su hábitat y sus recursos» (2009, p. 415). El sistema de representaciones es presentado por Golte como un sustituto de la escritura que evolucionó en los valles de la costa norcentral peruana y que, con el desarrollo paulatino de la cerámica, desemboca en la generación de una serie de cánones de expresión simbólica expresadas en el arte moche. Este sería tributario de una larga tradición iniciada en Cupisnique y Chavín, culturas en las que ya se aprecian elementos del mismo sistema básico de construcción de significados por medio de diademas, cinturones, bastones; imágenes-código también apreciables en el arte de Tiahuanaco y Wari (2009, p. 417). Además de asociarlo con un entorno geográfico específico, todo el desarrollo iconográfico y cosmológico moche se asocia con las llamadas fases IV y V, con lo que Golte sitúa, además, su análisis en un período histórico determinado. Tanto en Moche como en Nasca, Golte postula que tanto la descendencia como la producción y la reproducción de la sociedad resultan de la unión de contrarios El conjunto de la cosmovisión jerarquiza y apoya «la cooperación entre grupos que considera contrapuestos, antagónicos y diferentes» (2003, p. 215).

Sus análisis sobre sociedades específicas con importantes corpus iconográficos (Nasca, Moche, Wari) concluyen la pertenencia de todos ellos a una tradición panandina mayor, a una cosmología y una serie de códigos de comunicación con cientos o miles de años de profundidad, en último término a un lenguaje o universo cultural andino, entendido en sentido amplio, y que ha mostrado una gran continuidad en el tiempo y que Golte desentraña asociando y reconociendo Golte los aportes de Zuidema (1989), Hocquenguem (1987) y Sánchez (2015). El análisis iconográfico devela para Golte una serie de significados y discursos coherentes que permanecen en el tiempo, que pasan de la iconografía prehispánica, a las crónicas coloniales y a los mitos y relatos registrados en el siglo XX. La genealogía que parte de dos seres contrapuestos, un creador celeste y diurno 
y, un reproductor subterráneo y nocturno, con múltiple descendencia, se registra en los relatos coloniales en la jerarquía entre seres que se transforman en otros, que está también presente en mitos contemporáneos. Pasado fundante y seres con poder (kamaq) y relaciones fundadas en lógicas de parentesco y descendencia cruzan el tiempo y permanecen atemporalmente en el espacio, conformando un mundo sociomorfo, pero también situado e histórico $(2005$, p. 18).

\section{LOS CAMBIOS HISTÓRICOS Y LA NOCIÓN SUBYACENTE DE LA CULTURA (ANDINA)}

En 1980, la publicación del libro de Valderrama y Escalante (1979), Gregorio Condori Mamani, autobiografía, suscitó un debate académico acalorado sobre la vigencia de la cultura andina. Donde otros investigadores veían «vigencia», Golte enarbolaba el argumento de la «bancarrota» del sistema cognitivo andino, refiriéndose a la incapacidad del cargador cusqueño para comprender el mundo cambiante de la modernidad contemporánea.

Quiero cerrar esta lectura de los trabajos de Jürgen Golte abordando los sentidos subyacentes o explícitos del autor respecto de la cultura, en particular de la cultura andina. Es importante señalar que, de hecho, el autor utiliza numerosas veces el término cultura en los títulos de libros y artículos, y lo hace asociando el término a la migración, pero, sobre todo, a los procesos de transformación de la sociedad y la organización andinas.

En sus trabajos iconográficos, el pensamiento de Golte parece coincidir con las posiciones que el autor cuestiona en otros varios artículos. Trataremos de resolver esta aparente contradicción analizando tanto los implícitos sobre el concepto como los supuestos subyacentes del mismo en los trabajos analizados.

Una primera respuesta es proporcionada por el autor (Golte, 1996), cuando llama la atención sobre una paradoja inherente a distintos modelos o posturas sobre los estudios andinos: de un lado una sociedad historizada, que destaca características cambiantes de la sociedad en el tiempo (que el autor asigna a Rowe, pero que también podría asociarse a otros investigadores, como Mishkin e incluso a Murra); del otro, un análisis de estructuras cognoscitivas complejas e invariables, asociadas a la ocupación del espacio y el tiempo que asumen un orden invariable (que asimila a los trabajos de Zuidema o Hocquenhem). La paradoja se resuelve en el dinamismo y la identificación de espacios liminares, pero también de conjunción. Para Golte, el sistema categorial andino, aparentemente inmutable, implica una lógica de oposiciones de categorías en cuya conjunción o encuentro 
(tinkuy) proporciona salidas y soluciones. Así, el universo estructuralista «también puede ser leído como un plan de oposiciones, un universo de homologación de categorías, en la conjunción de las cuales se generan constantemente nuevas constelaciones de poder, de obligaciones mutuas en la vida diaria, de crecimiento de las plantas, de procreación de los animales y de hechos futuros de toda índole específica e histórica. Leída así, la paradoja inicial resulta ser aparente: la historia y la estructura categorial no se oponen, sino que se complementan» (1996, p. 528).

Pero podemos ensayar una respuesta más compleja en función de los contenidos que el autor asigna implícitamente a la noción de cultura. El dispositivo cultural desarrollado por Golte se centra en la construcción analítica de una forma de concebir y organizar tanto la producción como la sociedad misma; en ese sentido, desarrolla una noción de cultura que reúne una serie de características concretas que procuraremos enumerar.

En primer lugar, los desarrollos y análisis sobre la iconografía nasca y moche y las conclusiones y reflexiones derivadas de dicho análisis parecen apuntar inequívocamente a una noción de cultura como un sistema cognitivo, que transmite y lee símbolos y mensajes en un código de comprensión que cruza territorios y siglos (Golte, 2009); una noción semejante a la de Leach (1976) que postula que dos sociedades incluso hablando lenguas diferentes participan del mismo sistema cultural si son capaces de leer de la misma manera los mismos símbolos.

La cultura analizada por Golte tiene también un importante componente que podríamos llamar de «ubicación geográfica» y de construcción histórica fuertemente anclados en el espacio y en la necesidad de interacción múltiple con las bases materiales de reproducción de la sociedad: la cultura es un dispositivo de relacionamiento y de interacción estrecha y de largo plazo con el medio ambiente en la que se inscribe, algo semejante a los planteamientos de la relación entre sociedad y ambiente y las relaciones entre lo ideal y lo material planteados por Godelier (1992). La cultura es un dispositivo para el aprovechamiento de la naturaleza, ella modela sus instituciones y prácticas y también sus imaginarios y rituales: «Toda la cultura andina resulta ser un conjunto interdependiente en grado sumo de la naturaleza transformada en los milenios de desarrollo humano, de instituciones y rituales imbricados con ella, y conocimientos "almacenados" tanto en la naturaleza transformada como en las instituciones sociales y formas ritualizadas de interacción entre los hombres y entre ellos y la naturaleza» (Golte, 1992a, p. 447).

Pero es importante situar estos análisis en una cultura específica histórica y concreta: la cultura andina, sobre la que trabaja etnográfica y reflexivamente Golte. 
Los múltiples trabajos sobre sociedad, organización y cultura andinas se refieren a ella como un todo. La cultura andina es un conglomerado de organizaciones, instituciones, prácticas y cosmologías opuesto a la cultura criolla o la cultura europea, vistas también como conjuntos totalizantes, tal como se aprecia tanto en los textos sobre racionalidad, migración e incluso en los caballos de Troya, en donde habla de los migrantes andinos en la ciudad de Lima (1980, 1987, 2001). Cuando explica los cambios y la eliminación de las jerarquías étnicas, se refiere a la jerarquización estructural existente entre la cultura andina y la cultura criolla, en un sistema de siglos en las que una subordinaba a la otra, extrayendo de ella, trabajo y excedentes (Golte, 1995, p. 138).

Además, la cultura andina que describe inicialmente el autor es ante todo una cultura campesina, «aldeana», como la llama en repetidas ocasiones. Y ello supone una serie de características y limitaciones frente a las nuevas situaciones que le toca enfrentar en las ciudades. Una cultura aldeana supone para Golte la adscripción a una sociedad relativamente pequeña, adscrita a un territorio, con ciertos parámetros y lógicas de construcción de una cosmovisión con lógicas y pretensión de totalidad que abarcan toda la realidad existente e imaginable dentro de sus términos.

Paradójicamente, en sus análisis no enfatiza tanto su continuidad sino sobre todo sus transformaciones, posibilidades y límites y, eventualmente, su final. Los trabajos sobre migración a las ciudades, las respuestas productivas y sociales de inserción de los migrantes a las nuevas situaciones, aprovechando sus redes étnicas, y sus prácticas culturales expresan la creación de una nueva cultura urbana próspera, una suerte de cultura «andina» ampliada (2001, p. 119). Los cambios impuestos por la modernidad, el crecimiento poblacional y la intrusión del mercado proporcionan nuevos parámetros. La regulación de la economía informal de los migrantes es provista por el mercado y no por la cultura.

Las influencias y tradiciones encontradas se multiplican, y es por ello que Golte postula el tránsito de una sociedad bicultural — es decir, andino-criollaa otra multicultural, basada en principios capitalistas e influencias culturales diversas y dispersas (2001, p. 108). Y en este contexto, los hijos y nietos de los migrantes, habitantes de la gran Lima, experimentan un «cambio brusco», el anclaje en los valores de la sociedad campesina no es adecuado para solucionar los problemas que enfrentan, y deben adquirir conocimientos de otros orígenes, fuera de los ámbitos familiares y redes de paisanaje, y todo ello implica un cambio en las bases culturales de la sociedad. La complejidad de las nuevas vidas en las mega ciudades globalizadas exige que seamos «polifacéticos» (2011, pp. 66, 74-75). 
Pero, ante todo, para Golte una cultura debe tener la capacidad de formular nuevas respuestas técnicas, para la relación entre la sociedad y la naturaleza: «La cultura podría ser definida como el acumulado conjunto de soluciones a problemas surgidos en el desarrollo de una sociedad. Estas soluciones incluirían no solamente las respuestas técnicas a los retos históricos sino y esto quizás resulta más importante, la organización del enfrentamiento de la sociedad con la naturaleza, y de hombres con otros hombres; es decir, la creación, el procesamiento y la transmisión de conocimiento» (1981, p. 59).

En la respuesta a sus críticas al texto de Gregorio Condori Mamani, enfatiza las limitaciones de respuesta tecnológica de la cultura aldeana andina, atacando directamente la lectura en términos únicamente «míticos» o desde la «humildad runa» de la cultura andina: se preocupa de que esta cultura encuentre efectivamente respuestas al contexto cambiante que el mismo Golte encontraría más de treinta años después en trabajos como el de las alasitas (Golte y Gabriel, 2014), en la que los andinos le (nos) muestran la generación de algunas respuestas para enfrentar la modernidad, e incluso la globalización.

Ciertamente, los imaginarios actuales no tienen la misma coherencia del discurso aldeano andino: la problemática diversa que enfrentamos, que no percibimos más que vagamente resulta desarraigada y dispersa e interpretada por discursos que apuntan a distintas explicaciones: la del tecnócrata «que quiere incorporar el país eficientemente al sistema de producción mundial»; la de las izquierdas, que apuntan a las formas de subsistencia material y sus consecuencias para el país», y la de la población de a pie, «que se abalanza sobre las instituciones educacionales» (1980b, p. 18).

\section{BIBLIOGRAFÍA CITADA}

\section{Trabajos de J. Golte}

Golte, J. (2014). 50 años de reorientación de los trabajos del IEP: las sociedades campesinas y la migración a las ciudades. En M. Tanaka (ed.), 50 años pensando el Perú. Una reflexión crítica. El Instituto de Estudios Peruanos, 1964-2014 (pp. 35-62). Lima: IEP.

Golte, J. (2014). La guerra de objetos contra los moche. Antropología: Cuadernos de Investigación, 13, 103-122.

Golte, J. (2013). Ciudad y ciudadanía: dos ideas en debate. Revista de Antropología / Época 4, 7 (Ene. 2013), 55-66. 
Golte, J. (2009). Moche: cosmología y sociedad. Una interpretación iconográfica. Lima: IEP, CBC.

Golte, J (2008). La modelación de una cosmología. Scientia, Universidad Ricardo Palma, 10(10), 1-36.

Golte, J. (2005). La construcción de la naturaleza en el mundo prehispánico andino, su continuación en el mundo colonial y en la época moderna. Revista de antropología, 3, Año 3, 2005, 13-61.

Golte, J. (2004). Divinidades femeninas moche. En Dorothea Ortmann (ed.), Anuario de Ciencias de la Religión: Las religiones en el Perú de hoy (pp. 165-220). Lima: Universidad Nacional Mayor de San Marcos, CONCYTEC.

Golte, J. (2003). La iconografía Nazca. Arqueológicas. Instituto de Investigaciones Arqueológicas, 26, 179-218.

Golte, J. (2003b). La diversidad de los Andes pre coloniales, sus consecuencias para los modos de incorporación a la Colonia y la diversidad regional y étnica en el presente. Investigaciones sociales UNMSM, 7(11), 11-39. https://doi. org/10.15381/is.v7i11.8102

Golte, J. (2001) Cultura, racionalidad y migración andina. Colección Mínima, 46. Lima: IEP.

Golte, J. (1999). Redes étnicas y globalización. Revista de Sociología UNMSM, 11(12). Recuperado de https://sisbib.unmsm.edu.pe/bibvirtual/publicaciones/sociologia/1999 n12/art041.htm

Golte, J. (1996). Una paradoja en la investigación etnohistórica andina. En M. Baumann (ed.), Cosmología y música en los Andes (pp. 519-531). Madrid: Iberoamericana.

Golte, J. (1995). Nuevos actores y culturas antiguas. En J. Cotler (ed.), Perú 1964-1994: economía, sociedad y politica (pp. 135-148). Lima: IEP.

Golte, J. (1994a). Los dioses de Sipán 2. La rebelión contra el Dios Sol. Lima: IEP.

Golte, J. (1994). Iconos y narraciones: la reconstrucción de una secuencia de imágenes Moche. Lima: IEP.

Golte, J. (1993). Los dioses de Sipán. Las aventuras del Dios Quismique y su ayudante Murrup. Lima: IEP (2018, 2da ed.)

Golte, J. (1992). Los problemas con las «comunidades». Debate Agrario, 14, Jun-set, pp. 17-22.

Golte, J. (1992a). Cultura y naturaleza andinas. En E. Kingman (comp.), Ciudades de los andes: visión histórica y contemporánea (pp. 439-456). Quito: IFEA-Ciudad.

Golte, J. (1985). Recolectores de caracoles en la cultura Moche (Perú). Indiana IberoAmerikanisches Institut, 10, 555-370. 
Golte, J. (1981). ¿Qué es la cultura frente a la historia? (Respuesta a Juan Ossio y Henrique Urbano). La Revista, 4. Lima.

Golte, J. (1981a). Cultura y naturaleza andinas. Allpanchis, 13 (17/18), 119-132. https:// doi.org/10.36901/allpanchis.v13i17/18.1131

Golte, J. (1980). La racionalidad de la organización andina. Colección Mínima 9. Lima: IEP [1987] (segunda edición).

Golte, J. (1980a). Repartos y rebeliones. Túpac Amaru y las contradicciones de la economía colonial. Lima: IEP [2016] (segunda edición).

Golte, J. (1980b). Gregorio Condori Mamani o la bancarrota del sistema cognitivo andino. La Revista, 3. Lima.

Golte, J. y Adams, N. (1987). Los caballos de Troya de los invasores: estrategias campesinas en la conquista de la gran Lima. Urbanización, Migraciones y Cambios en la Sociedad Peruana, 9. Lima: IEP, 1990 (segunda edición). Recuperado de https://repositorio.iep.org.pe/handle/IEP/695

Golte, J. y De la Cadena, M. (1986). La codeterminación de la organización social andina. Documento de Trabajo $\mathrm{N}^{\circ}$ 13. Lima: IEP [1983].

Golte, J. y De la Cadena, M. (1983). La codeterminación de la organización social andina. Allpanchis, 15(22), 7-34. https://doi.org/10.36901/allpanchis.v15i22.907

Golte, J. y Degregori, C.I. (1973). Dependencia y desintegración estructural en la comunidad de Pacaraos. Estudios Etnológicos del Valle de Chancay, 3. Lima: IEP.

Golte, J., Degregori, C., Gálvez, M. y Urrutia, J. (1967). Cambios estructurales y limitaciones ecológicas: proceso histórico de la comunidad de Santa Lucía de Pacaraos. Estudios Etnológicos del Valle de Chancay, 5. Lima: IEP, Cornell University, UNMSM, Facultad de Letras, Departamento de Antropología.

Golte, J. y León, D. (2014). Alasitas: discursos, prácticas y símbolos de un «liberalismo aymara altiplánico» entre la población de origen migrante en Lima. Lima: IEP.

Golte, J. y León, D. (2011). Polifacéticos: jóvenes limeños del siglo XXI. Sociedad y Actualidad. Lecturas Contemporáneas, 14. Lima: IEP, ATOQ.

\section{Obras de otros autores}

Bourget, S. (2006). Sex, death, and sacrifice in Moche religion and visual culture. Austin: University of Texas.

Diez, A. (2014). Cambios en la ruralidad y en las estrategias de vida en el mundo rural. Una relectura de antiguas y nuevas definiciones. En Sepia XV (ed.), Perú el problema agrario en debate (pp. 19-85). Lima: SEPIA. 
Degregori, C. I. (ed.) (2000). No hay país más diverso. Compendio de antropología peruana. Lima: Red para el Fomento de las Ciencias Sociales.

Dollfus, O. (1981). El reto del espacio andino. Lima: IEP.

Donnan, C. y McClelland, D. (1999). Moche fine Unepainting: Its Evolution and its artists. Los Angeles: Fowler Museum of Cultural History.

Figueroa., A. (1981). La economía campesina de la sierra del Perú. Lima: PUCP.

Fuenzalida, F., , Valiente, T., Villarán, J. L., Golte, J., Degregori, C. I y Casaverde, J. (1982). El desafio de Huayopampa: comuneros y empresarios. Lima: IEP [segunda edición].

Fuenzalida, F., Villarán, J. L., Golte, J. y Valiente, T. (1968). Estructuras tradicionales y economía de mercado: la comunidad de indígenas de Huayopampa. Estudios Etnológicos del Valle de Chancay, 1. Lima: IEP.

Giarraca, N. (comp.). (2001). ¿Una nueva ruralidad en América Latina? Buenos Aires: Clacso.

Godelier, M. (1989). Lo ideal y lo material. Pensamiento, economías, sociedades. Madrid: Taurus.

Hocquenghem, A. M. (1987). Iconografía mochica. Lima: Pontificia Universidad Católica del Perú.

Leach, E. (1976). Sistemas políticos de la alta Birmania. Estudio sobre la estructura social kachin. Barcelona: Anagrama.

Levi Strauss, C. (1979). Antropología estructural. Mito, sociedad, humanidades. México: Siglo XXI.

Murra, J. (1975). Formaciones económicas y politicas del mundo andino. Lima: IEP.

Plaza, O. y Francke, M. (1981). Formas de dominio, economía y comunidades campesinas. Lima: Desco.

Sánchez, R. (2015). Apus de los cuatro suyus. Construcción del mundo en los ciclos mitológicos de los dioses montaña. Lima: IEP-CBC.

Tanaka, M. (ed.) (2014). 50 años pensando el Perú: una reflexión crítica: el Instituto de Estudios Peruanos, 1964-2014. Lima: IEP.

Urrutia, J. (1992). Antropología y comunidades. Historia de un amor (casi) eterno. Debate Agrario, 14, jun-set, 1-16.

Valderrama, R. y Escalante, C. (1979). Gregorio Condori Mamani, autobiografía. Cusco: CBC.

Zuidema, T.(1989). Reyes y guerreros: ensayos de cultura andina. Lima: FOMCIENCIAS. 